\title{
Sistema radicular da soja em função da compactação do solo no sistema de plantio direto
}

\author{
Eduardo Garcia Cardoso(1), Lincoln Zotarelli(2), Jorge Luiz Piccinin ${ }^{(3)}$, Eleno Torres ${ }^{(3)}$, \\ Odilon Ferreira Saraiva ${ }^{(3)}$ e Maria de Fátima Guimarães ${ }^{(4)}$
}

\begin{abstract}
(1)Universidade Estadual de Ponta Grossa, Dep. de Agronomia, Av. General Carlos Cavalcanti, № 4.748, CEP 84030-900 Ponta Grossa, PR. E-mail: edugcardoso@yahoo.com.br (2)University of Florida, Agronomy Department, P.O. Box 110965, $32611-0965$ Gainesville, FL, EUA. E-mail: Izota@ufl.edu (3)Embrapa Soja, Caixa Postal 1.061, CEP 86001-970 Londrina, PR. E-mail: piccininjlp@bol.com.br, eleno@cnpso.embrapa.br, odilon@cnpso.embrapa.br ${ }^{(4)}$ Universidade Estadual de Londrina, Centro de Ciências Agrárias, Caixa Postal 6.001, CEP 86051-990 Londrina, PR. E-mail: mfatima@uel.br
\end{abstract}

\begin{abstract}
Resumo - O objetivo deste trabalho foi avaliar os efeitos da compactação do solo sobre suas propriedades morfoestruturais e sobre o desenvolvimento radicular da soja, sob sistema plantio direto, em um experimento conduzido num Latossolo Vermelho distroférrico, em Londrina, PR. O delineamento utilizado foi o de blocos ao acaso, com parcelas subdivididas e quatro repetições. Foram constituídos dois tratamentos de manejo nas parcelas: um em solo escarificado à profundidade de $20-25 \mathrm{~cm}$, com densidade do solo de $1,17 \mathrm{Mg} \mathrm{m}^{-3}$; e outro em solo compactado, a $12 \mathrm{~cm}$ de profundidade, e densidade de 1,38 $\mathrm{Mg} \mathrm{m}^{-3}$. Nas subparcelas, foram semeadas duas cultivares de soja, Embrapa-4 e BR-16. A presença de camadas mais compactas no perfil do solo provocou o desenvolvimento radicular em zonas de menor resistência, em poros biológicos e nas fissuras do solo. A produção de grãos não apresentou diferença entre os tratamentos, graças à adequada disponibilidade hídrica durante o período avaliado. A cultivar Embrapa-4 apresentou maior crescimento radicular em estruturas compactas, comparada à cultivar BR-16.
\end{abstract}

Termos para indexação: caracterização morfoestrutural do solo, distribuição de raízes, resistência do solo à penetração.

\section{Soybean root system in function of soil compaction under no-tillage system}

\begin{abstract}
An experiment was carried out on a Rhodic Ferralsol, in Londrina, PR, to evaluate the soil compaction effects on soil morphostructure and on soybean root distribution, under no-tillage system. The field experiment was arranged in a completely randomized block (split plot) design with four replicates, and with the compacted treatments in the main plots and soybean varieties in subplots. The treatments were: one scarified soil until 20-25 cm depth layer with bulk density of $1.17 \mathrm{Mg} \mathrm{m}^{-3}$, and one compacted soil with bulk density of $1.38 \mathrm{Mg} \mathrm{m}^{-3}$, in a $12 \mathrm{~cm}$ depth. Two varieties of soybean, Embrapa-4 and BR-16, were cultivated on subplots. Roots developed in zones with less resistance of penetration and in biological tunnels. The soybean grain yield was not different under compacted and noncompacted soil, because soil water moisture was adequate. Embrapa-4 showed greater root density than BR-16.
\end{abstract}

Index terms: morphostrutural characterization, root distribution, soil resistance to penetration.

\section{Introdução}

O desenvolvimento de novas tecnologias e de técnicas de manejo do solo possibilitaram a expansão da área de cultivo da soja, nas últimas décadas no Brasil. No sistema de plantio direto (SPD), o acúmulo de resíduos culturais na superfície do solo acarreta diferenças, em relação a outros sistemas de manejo, na distribuição dos nutrientes no perfil do solo (Muzilli, 1983; Lipiec \&
Stepniewski, 1995), na dinâmica da matéria orgânica (Freixo et al., 2002) e da água (Torres \& Saraiva, 1999; Sadras et al., 2005), e na estruturação do solo (Franzluebbers, 2002; Bronick \& Lal, 2005), que podem influenciar o crescimento e distribuição do sistema radicular.

O manejo do solo no SPD induz a transformações e reorganizações morfoestruturais do perfil do solo, com redução da macroporosidade (Bronick \& Lal, 2005), o 
que reflete numa diferenciação da colonização do volume do solo explorado pelas raízes, se comparado ao sistema de preparo com arados. Segundo Johnson et al. (1990), no SPD a compactação superficial do solo pode apresentar correlação negativa com a produtividade, em razão de maior resistência mecânica oferecida ao desenvolvimento das raízes entre agregados e intra-agregados (Piccinin et al., 2000).

O crescimento radicular da soja ocorre quando células da região meristemática sofrem divisão e alongamento, por meio da pressão de turgor nas células, que é a força direcional para se sobrepor a qualquer resistência externa (Camargo \& Alleoni, 1997). Além disso, as raízes são flexíveis, lubrificadas e podem alterar a direção para ultrapassar obstáculos, como agregados ou estruturas mais adensadas (Vepraskas, 1994). Apesar disso, o impedimento mecânico causado pela compactação pode provocar decréscimo na taxa de elongação celular (Bengough \& Mullins, 1990), em função da baixa atividade biológica, ausência quase completa de orifícios e pouca porosidade nas estruturas compactadas (Tavares Filho et al., 1999). Além da compactação, a temperatura, a umidade, a aeração e a disponibilidade de nutrientes também podem inibir o crescimento radicular (Camargo \& Alleoni, 1997).

Aproximadamente 70 a $80 \%$ da massa das raízes de soja distribuem-se nos primeiros $15 \mathrm{~cm}$ do solo, em condições normais de cultivo (Gregory, 1992), com o desenvolvimento radicular da soja ocorrendo através dos macroporos ou dos espaços vazios entre os agregados (Abreu et al., 2004). A continuidade desses espaços vazios, considerados fundamentais para o aprofundamento das raízes, é decorrente da presença de estruturas mais frágeis, fendas - originadas dos movimentos de contração e expansão da fração coloidal e de canais formados pelas raízes em decomposição e pela atividade biológica da fauna do solo (Neves et al., 2003; Holland, 2004). Esses processos estão intimamente associados ao manejo do solo nas operações de preparo, rotação de culturas e atividades de descompactação (Torres \& Saraiva, 1999).

O processo de compactação tem conceitos baseados em relações volumétricas e nas características texturais do solo (Reichardt, 1985). Contudo, generalizações não devem ser feitas, uma vez que a compactação não tem ocorrência contínua numa determinada camada. O rearranjo da estrutura do solo, decorrente da compactação, se reflete no crescimento das raízes, que tendem a concentrar-se na camada superficial do solo, até $10 \mathrm{~cm}$ de profundidade (Lal, 1989).
No SPD, Genro Junior et al. (2004) observaram maior compactação nas camadas superficiais, comparado aos sistemas que envolveram a mobilização do solo entre 0,20 e 0,30 m de profundidade. $\mathrm{O}$ aumento da resistência do solo reduz ou até cessa o desenvolvimento radicular, dependendo da espécie (Beulter \& Centurion, 2003).

O objetivo deste trabalho foi avaliar os efeitos da compactação do solo nas propriedades morfoestruturais e no desenvolvimento radicular da soja, sob sistema plantio direto.

\section{Material e Métodos}

O experimento foi realizado na área experimental da Embrapa Soja, no Município de Londrina, PR (2312'S e $51^{\circ} 11^{\prime} \mathrm{W}$, altitude de $585 \mathrm{~m}$ e clima $\mathrm{Cfa}$, segundo Köppen), durante a safra de verão 2001/2002. O solo da área experimental foi classificado como Latossolo Vermelho distroférrico, horizonte A moderado e textura muito argilosa (787 $\mathrm{g} \mathrm{kg}^{-1}$ de argila e $168 \mathrm{~g} \mathrm{~kg}^{-1}$ de silte) (Embrapa, 1997).

O delineamento experimental utilizado foi o de blocos ao acaso, em parcelas subdivididas de $180 \mathrm{~m}^{2}$, com quatro repetições. Os sistemas de manejo do solo avaliados foram: plantio direto compactado (SPDC), em solo submetido a tráfego intenso, com densidade em torno de $1,38 \mathrm{Mg} \mathrm{m}^{-3}$, na profundidade de $12 \mathrm{~cm}$; e plantio direto não compactado (SPDNC), em solo escarificado a 20-25 cm de profundidade, na implantação do experimento, com densidade de $1,17 \mathrm{Mg} \mathrm{m}^{-3}$, na profundidade de $12 \mathrm{~cm}$.

Na subparcela, foram semeadas as cultivares de soja Embrapa-4 e BR-16, em 13/11/2001, com 0,45 m entre linhas e 18 plantas por metro linear. Foram aplicados, no sulco de semeadura, $60 \mathrm{~kg} \mathrm{ha}^{-1}$ de $\mathrm{P}_{2} \mathrm{O}_{5}$ e $60 \mathrm{~kg} \mathrm{ha}^{-1}$ de $\mathrm{K}_{2} \mathrm{O}$, na forma de adubo formulado (0-20-20), conforme a análise do solo. Foi feita a inoculação de Bradyrhizobium japonicum e B. elkanii estirpe SEMIA 587 + SEMIA 5019, na proporção de 200 g de inoculante comercial para cada $60 \mathrm{~kg}$ de sementes. Foi feito tratamento fitossanitário nas sementes de soja, para controle de Rhizoctonia solani e Fusarium semitectum, com fungicida dissulfeto de tetrametil tiuran, na dose recomendada.

As avaliações de raízes e caracterização morfoestrutural foram realizadas durante o estádio de desenvolvimento R2 da soja, em trincheiras perpendiculares à linha de cultivo, com $100 \mathrm{~cm}$ de largura por $70 \mathrm{~cm}$ de profundidade, abrangendo duas plantas. Nesse estádio, foi avaliada, também, a acumulação de matéria seca, tendo sido coletadas oito plantas por parcela 
aos 70 dias após emergência, secadas em estufa de circulação forçada de ar, a $60^{\circ} \mathrm{C}$, até peso constante, para, posteriormente, serem pesadas em balança eletrônica modelo Micronal B-1600.

A quantificação do sistema radicular foi realizada conforme Bohm (1979), com uma tela com quadrículos de $5 \mathrm{~cm}$ de lado. A descrição morfoestrutural dos perfis dos tratamentos SPDNC e SPDC foi realizada segundo o perfil cultural (Tavares Filho et al., 1999), que resultou na descrição de seis organizações (Tabela 1).

Foram coletadas amostras não-deformadas de solo, das camadas de $0-12,12-20$ e $20-28 \mathrm{~cm}$ de profundidade, com o uso de cilindros de aço inoxidável com diâmetro e altura de $5 \mathrm{~cm}$ (Blake \& Hartge, 1986), para determinação da densidade, macroporosidade e microporosidade pelo método da mesa de tensão (Embrapa, 1997).

A análise química foi realizada em amostras das camadas de $0-5,5-10,10-15,15-20,20-30$ e 30-40 cm de profundidade, conforme Embrapa (1997). A colheita de grãos de soja foi realizada, mecanicamente, numa área de $5,4 \mathrm{~m}^{2}$, com a umidade corrigida para $13 \%$.
Os dados obtidos foram submetidos à análise de variância, e a comparação de médias entre os tratamentos foi realizada pelo teste LSD de Student a 5\% de probabilidade.

\section{Resultados e Discussão}

A produção de grãos e a acumulação de matéria seca das plantas de soja não diferiram significativamente, em função da compactação do solo, para as cultivares avaliadas. A média da produtividade da soja foi de 3,27 Mg ha-1, valor próximo ao esperado para a região, enquanto a média da matéria seca da parte aérea foi de 5,4 $\mathrm{Mg} \mathrm{ha}^{-1}$. De acordo com Secco et al. (2004), num Latossolo Vermelho distroférrico (108 g kg-1 de areia e $427 \mathrm{~g} \mathrm{~kg}^{-1}$ de argila) valores de resistência do solo até 2,60 MPa e densidade $1,51 \mathrm{Mg} \mathrm{m}^{-3}$, na camada até $0,20 \mathrm{~m}$, não comprometeram o rendimento de grãos de soja, em condições de lavoura.

A análise química do solo evidenciou que as concentrações de Al, Ca, Mg, K e P foram semelhantes, entre os tratamentos, nas camadas avaliadas (Tabela 2), ten-

Tabela 1. Descrição das organizações estruturais do solo, pelo método do perfil cultural(1).

\begin{tabular}{ll}
\hline Organização estrutural & Descrição \\
\hline Sem coesão (SC) & $\begin{array}{l}\text { Estado estrutural sem coesão, formado de pequenos agregados granulares e grumosos, nítido, com vazios } \\
\text { de origem biológica (cavidades e tubulares) e resultantes do empilhamento de agregados. }\end{array}$ \\
$\begin{array}{l}\text { Estrutura fragmentar nítida, formada de agregados subangulares-médios/angulares-pequenos com vazios } \\
\text { de origem de atividade biológica (cavidades e tubulares) e fissuras. }\end{array}$ \\
$\begin{array}{l}\text { Estrutura fragmentar pouco nítida, formada por agregados subangulares-médios/angulares de muito peque- } \\
\text { nos a pequenos, com vazios de origem biológica (tubular) e empilhamento de agregados. }\end{array}$ \\
$\begin{array}{l}\text { Estrutura fragmentar nítida, formada de agregados subangulares-médios/subangulares-pequenos, vazios } \\
\text { origem biológica (cavidades e tubular) e fissuras. }\end{array}$ \\
Baixa compactação com fissura (BCCF) \\
Baixa compactação sem fissura (BCSF) \\
vazios com origem biológica (cavidades e tubulares) formado por empilhamento de agregados.
\end{tabular}

(1)Fonte: Tavares Filho et al. (1999).

Tabela 2. Caracterização química do solo, nos tratamentos sistema plantio direto compactado (SPDC) e sistema plantio direto não compactado (SPDNC).

\begin{tabular}{|c|c|c|c|c|c|c|c|c|c|c|c|}
\hline $\begin{array}{l}\text { Profundidade } \\
(\mathrm{cm})\end{array}$ & $\begin{array}{c}\mathrm{pH} \\
\left(\mathrm{H}_{2} \mathrm{O}\right)\end{array}$ & $\mathrm{Al}$ & $\mathrm{H}+\mathrm{Al}$ & $\mathrm{Ca}$ & $\underset{\mathrm{mol}_{\mathrm{c}} \mathrm{dr}}{\mathrm{Mg}}$ & $\mathrm{K}$ & CTC & SB & $\begin{array}{c}\mathrm{V} \\
(\%)\end{array}$ & $\begin{array}{c}\mathrm{C} \\
\left(\mathrm{g} \mathrm{dm}^{-3}\right)\end{array}$ & $\begin{array}{c}\mathrm{P} \\
\left(\mathrm{mg} \mathrm{dm}^{-3}\right)\end{array}$ \\
\hline \multicolumn{12}{|c|}{ SPDC } \\
\hline $0-5$ & 5,11 & 0,00 & 5,20 & 5,40 & 1,58 & 0,81 & 13,00 & 7,8 & 59,9 & 25,0 & 31,6 \\
\hline $5-10$ & 4,90 & 0,05 & 4,98 & 4,65 & 1,21 & 0,74 & 11,60 & 6,6 & 57,9 & 21,6 & 28,5 \\
\hline $10-15$ & 5,05 & 0,00 & 4,66 & 5,05 & 1,22 & 0,55 & 11,50 & 6,8 & 59,4 & 20,2 & 9,2 \\
\hline $15-20$ & 5,21 & 0,00 & 4,50 & 5,11 & 1,28 & 0,42 & 11,30 & 6,7 & 60,1 & 18,8 & 7,1 \\
\hline $20-30$ & 5,34 & 0,00 & 3,90 & 4,58 & 1,29 & 0,32 & 10,10 & 6,2 & 61,2 & 14,8 & 5,4 \\
\hline $30-40$ & 5,42 & 0,00 & 3,60 & 4,10 & 1,23 & 0,25 & 9,20 & 5,6 & 60,5 & 11,5 & 6,0 \\
\hline \multicolumn{12}{|c|}{ SPDNC } \\
\hline $0-5$ & 5,25 & 0,00 & 4,82 & 5,93 & 1,58 & 0,84 & 13,16 & 8,3 & 63,4 & 25,2 & 35,4 \\
\hline $5-10$ & 5,00 & 0,02 & 5,46 & 5,32 & 1,25 & 0,72 & 12,76 & 7,3 & 57,2 & 21,3 & 32,1 \\
\hline $10-15$ & 5,12 & 0,00 & 4,91 & 5,46 & 1,24 & 0,61 & 12,22 & 7,3 & 59,7 & 20,5 & 17,4 \\
\hline $15-20$ & 5,24 & 0,00 & 4,44 & 5,43 & 1,23 & 0,52 & 11,62 & 7,2 & 61,6 & 18,0 & 8,9 \\
\hline $20-30$ & 5,44 & 0,00 & 3,94 & 5,10 & 1,28 & 0,41 & 10,72 & 6,8 & 63,2 & 15,0 & 8,4 \\
\hline $30-40$ & 5,58 & 0,00 & 3,63 & 4,55 & 1,30 & 0,33 & 9,81 & 6,2 & 63,0 & 11,2 & 6,2 \\
\hline
\end{tabular}


do-se mostrado ainda adequadas para o desenvolvimento da soja (Embrapa, 2000; Sadras et al., 2005). Cabe destacar que, na camada de $0-10 \mathrm{~cm}$ de profundidade, os teores de $\mathrm{P}$ encontravam-se de duas a três vezes mais altos que os teores encontrados nas camadas abaixo de $10 \mathrm{~cm}$, o que concorda com Rheinheimer \& Anghinoni (2001).

De acordo com Lipiec \& Stepniewski (1995), o efeito da compactação, sobre o transporte de nutrientes para a raiz, depende da intensidade da compactação do solo e do suprimento de água e nutrientes. Não foi observada restrição de precipitação, que foi bem distribuída durante o período, num total de $678 \mathrm{~mm}$. Assim, a ausência de baixos valores de umidade do solo não contribuiu para o aumento da resistência deste à penetração das raízes (Genro Junior et al., 2004; Sadras et al., 2005).

Em relação às propriedades físicas, a densidade do solo no SPDC foi de 1,38 $\mathrm{Mg} \mathrm{m}^{-3} \mathrm{e}$ a macroporosidade, de $12,2 \%$, na camada de $8-16 \mathrm{~cm}$ de profundidade, e no SPDNC, a densidade do solo foi de $1,26 \mathrm{Mg} \mathrm{m}^{-3}$, com macroporosidade de $16,3 \%$ para a mesma profundidade (Tabela 3).

O somatório do volume de raízes foi diferente para as duas cultivares, em função dos tratamentos (Figura 1). Para a cultivar BR-16, o volume de raízes foi significativamente maior no SPDNC, entre 5 e $25 \mathrm{~cm}$ de profundidade, enquanto para a cultivar Embrapa-4, na profundidade de $10-25 \mathrm{~cm}$, o volume de raízes foi maior no SPDC, o que mostrou uma maior capacidade dessa cultivar em colonizar áreas compactadas. Com relação ao volume total de raízes, integrando o perfil do solo até $60 \mathrm{~cm}$ de profundidade, não houve diferença significativa entre os tratamentos SPDC e SPDNC, para a cultivar BR-16 (valores de $0,932 \mathrm{~cm} \mathrm{~cm}^{-3} \mathrm{e}$
$1,076 \mathrm{~cm} \mathrm{~cm}^{-3}$, respectivamente). Entretanto, para a cultivar Embrapa-4 houve diferença (valores de $1,315 \mathrm{~cm} \mathrm{~cm}^{-3}$ para o SPDC e $0,818 \mathrm{~cm} \mathrm{~cm}^{-3}$ para o SPDNC).

A distribuição das raízes foi diferente na cultivar BR-16, na profundidade de $15 \mathrm{~cm}$ e, na cultivar Embrapa-4 na profundidade de $25 \mathrm{~cm}$. Abaixo dessas profundidades, as cultivares apresentaram um decréscimo acentuado na quantidade de raízes (Figuras 1 e 2), o que concorda com os resultados de Beulter \& Centurion (2004). De acordo com esses autores, o aumento da densidade na camada $10-15 \mathrm{~cm}$ causou decréscimo linear na quantidade de raízes. A compactação do solo, detectada pelo maior valor de densidade no SPD, foi atribuída ao efeito cumulativo do tráfego de máquinas e à ausência de mobilização mecânica do solo (Tormena et al., 2002), o que possibilitou reduções na produtividade das culturas, quando da ocorrência de deficit hídrico nos estágios fenológicos críticos (Domzal \& Slowinska-Jurkiewicz, 1987).

As raízes apresentaram-se normais e com desenvolvimento preferencial no sentido vertical até aproximadamente $30 \mathrm{~cm}$. A distribuição diferenciada entre os tratamentos deu-se em função da localização e presença de determinadas estruturas compactadas (CSF e BCSF, Tabela 1), que impediram o desenvolvimento radicular (Figura 3 E, F, G e H).

Os valores de resistência do solo oscilaram de 1 a 4,5 MPa, na profundidade de 0-5 cm (Figura 3 A, B, C e D). Nessa camada de solo, assim como nas demais profundidades, não foi observada correlação entre valores de resistência à penetração e a quantidade de raízes. Um dos possíveis fatores responsáveis pela não-corre-

Tabela 3. Valores de densidade do solo, densidade de partícula, porosidade total, macroporosidade e microporosidade do solo, em três profundidades, em solo compactado e não compactado, em sistema plantio direto ${ }^{(1)}$.

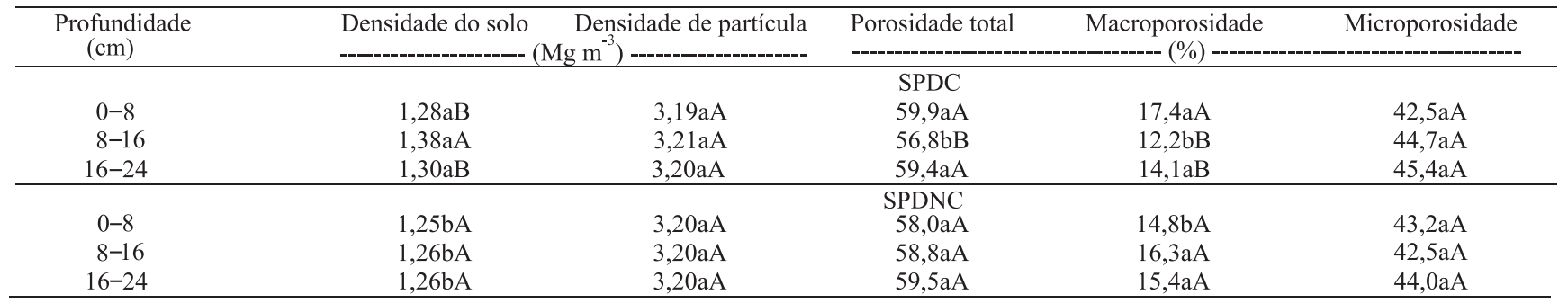

(1)Médias seguidas da mesma letra minúscula nas mesmas profundidades e da mesma letra maiúscula nas diferentes profundidades não diferem entre si pelo teste LSD de Student a $5 \%$ de probabilidade. 


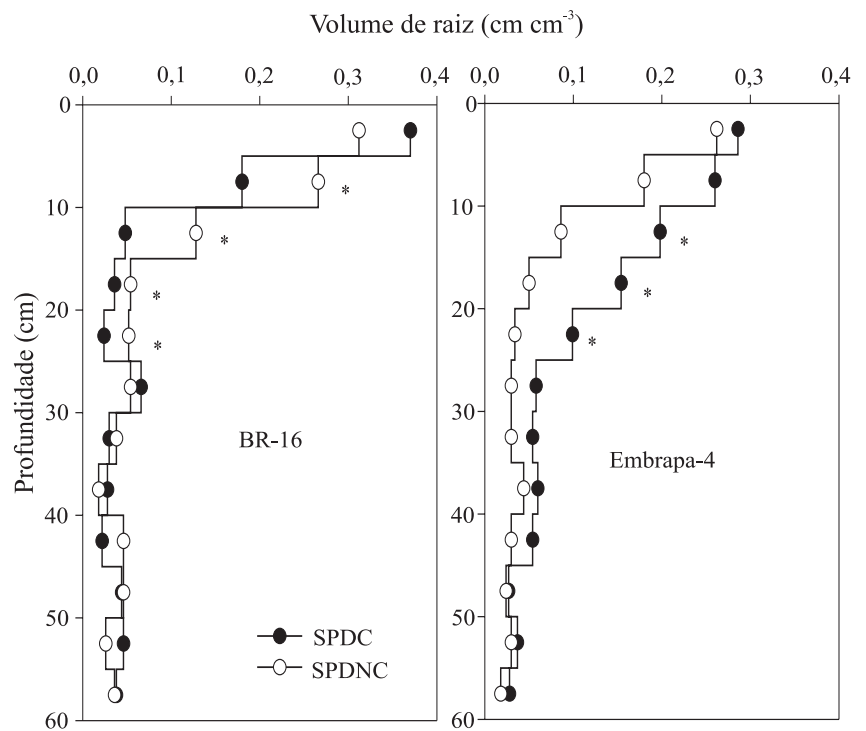

Figura 1. Somatório do volume $\left(\mathrm{cm} \mathrm{cm}^{-3}\right)$ de raízes de soja, por camada de $5 \mathrm{~cm}$ de profundidade, em $100 \mathrm{~cm}$ de largura do perfil solo, em função dos tratamentos: sistema plantio direto compactado (SPDC) e não compactado (SPDNC), para as cultivares BR-16 e Embrapa-4. Os pontos seguidos por asterisco diferem significativamente entre si a 5\% de probabilidade, pelo teste LSD de Student, dentro da mesma camada de solo. lação foi o fato de a avaliação pelo penetrômetro ser de caráter bidimensional, ou seja, foi avaliado apenas o plano da parede do perfil e, portanto, não foi considerada a resistência do solo em todas as áreas de abrangência do sistema radicular de uma mesma planta que, dependendo do diâmetro das raízes, pode explorar os poros do solo mais facilmente, como exemplo, raízes de pequeno diâmetro (Pietola, 2004).

Pela análise morfoestrutural (Figura 3 E, F, G e H) observou-se o desenvolvimento de fissuras nos tratamentos SPDC e no SPDNC, nas camadas de 0-25 cm e $0-15 \mathrm{~cm}$ de profundidade, respectivamente. As fissuras mostraram-se mais desenvolvidas nas áreas sob SPDC, principalmente nos primeiros $15 \mathrm{~cm}$ de profundidade que permitiram o desenvolvimento das raízes nas camadas compactadas. Este fator esteve, provavelmente, relacionado com o aumento da densidade do solo, onde à medida que o processo de compactação progrediu, os agregados se compactaram, reduzindo a quantidade de vazios intra-agregados. Assim, as oscilações da temperatura e de umidade do solo, associadas à coesão dos minerais de argila, promovem o desenvolvimento de fissuras entre as faces dos agre-

Largura do perfil $(\mathrm{cm})$

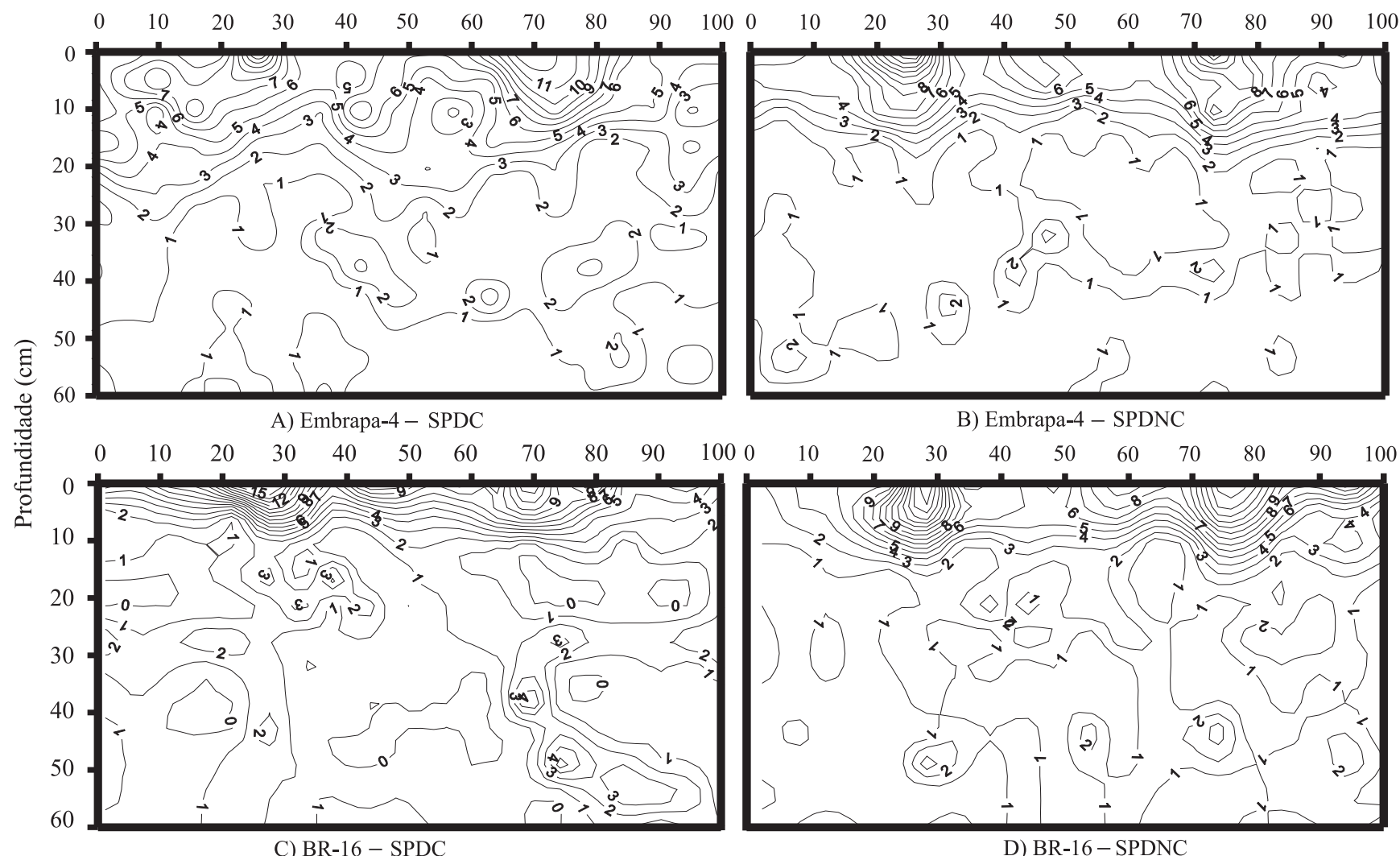

Figura 2. Distribuição do volume $\left(\mathrm{cm} \mathrm{cm}^{-3}\right)$ de raízes de soja, no perfil do solo, em função da compactação. 

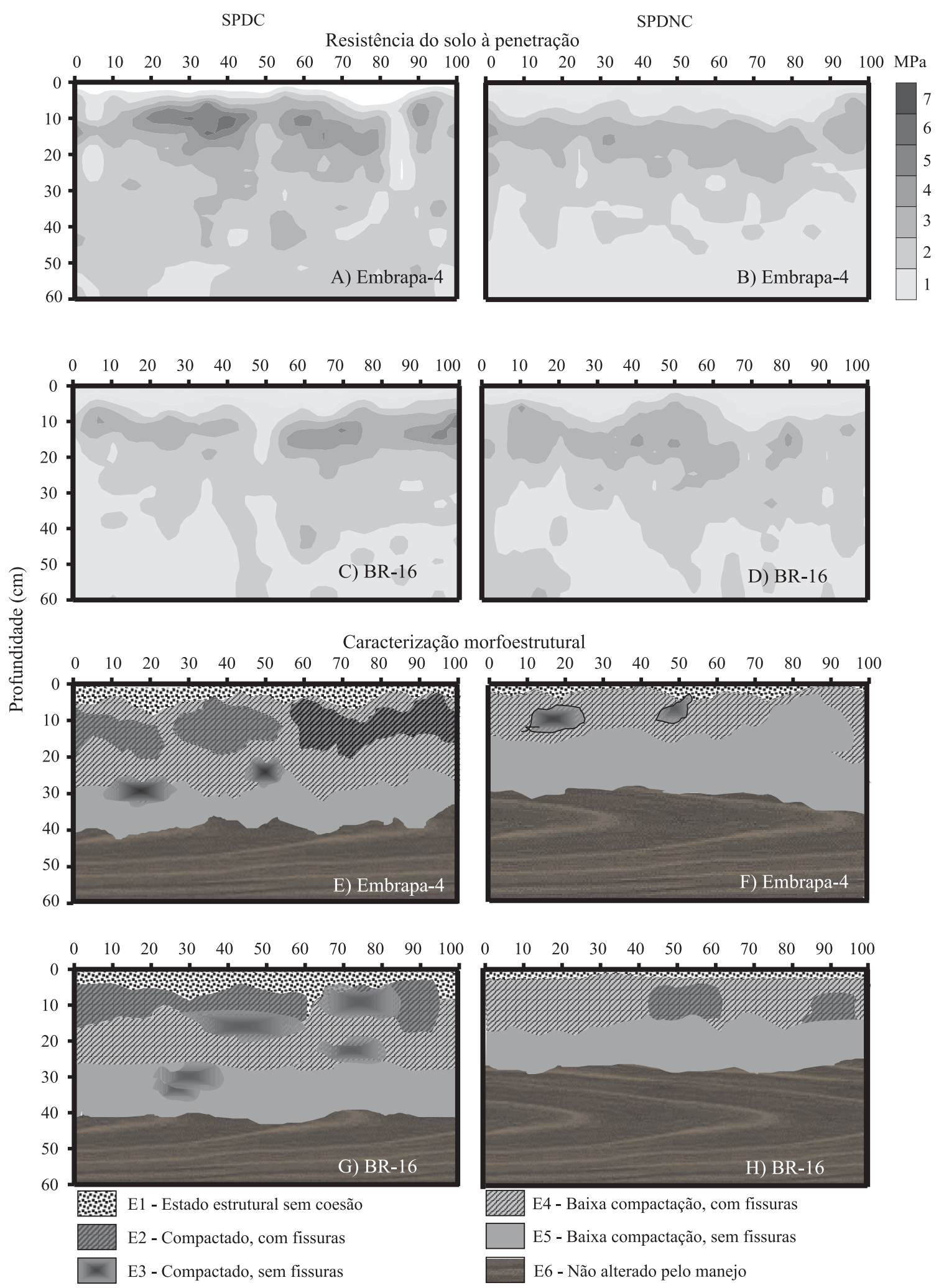

Figura 3. Resistência do solo à penetração e caracterização morfoestrutural no perfil do solo, no tratamento com as cultivares Embrapa-4 e BR-16, em sistema de plantio direto compactado (SPDC) e não compactado (SPDNC). 
gados característicos do Latossolo Vermelho (Piccinin et al., 2000). Este processo mostrou-se mais expressivo nas estruturas formadas por agregados angulares, com baixa ocorrência de vazios intra-agregados (CCF), associados a maiores valores de densidade do solo (1,38 $\left.\mathrm{Mg} \mathrm{m}^{-3}\right)$.

No SPDC, a maior concentração radicular ocorreu na camada até $5 \mathrm{~cm}$, diminuindo gradativamente até $20 \mathrm{~cm}$ de profundidade (Figuras 1e 2). Sadras et al. (2005) observaram que o crescimento radicular foi reduzido e o comprimento radicular diminuiu gradativamente na camada subsuperficial do solo, refletindo mudanças morfológicas das raízes, em função da compactação do solo.

Neste mesmo tratamento, a estrutura SC ocorreu de forma mais generalizada no espaço do perfil até a profundidade de $7 \mathrm{~cm}$. Abaixo desta camada, foi observada a presença da CSF (de ocorrência não contínua horizontalmente, entre 5 e $10 \mathrm{~cm}$ de profundidade, com densidade de solo de 1,38 $\mathrm{Mg} \mathrm{m}^{-3}$ ), tendo resultado em menor volume de raízes (Figura 4), que contornaram esta estrutura, mesmo esta não apresentando densidade de solo elevada (Reichardt, 1985).

Juntamente com a CSF, observou-se a corrência da CCF, entre 0 e $16 \mathrm{~cm}$ de profundidade, predominantemente a $8 \mathrm{~cm}$, com densidade de $1,38 \mathrm{Mg} \mathrm{m}^{-3}$, o que resultou numa maior colonização radicular (Figura 4). Entretanto, pela avaliação de penetrometria, as duas estruturas apresentaram uma variação de resistências semelhantes, indicando que o penetrômetro não foi sensível à diferenciação das duas estruturas. Entre as cultivares, a Embrapa-4 teve maior capacidade de colonização de raízes que a BR-16, nas estruturas CSF e CCF, independentemente da resistência do solo à penetração.

Na camada de $0-5 \mathrm{~cm}$ de profundidade, no SPDNC, a morfologia das raízes foi relacionada à transição da estrutura SC para BCCF. O comportamento da raiz principal da soja deu-se, preferencialmente, no sentido vertical, e as raízes laterais no sentido vertical/horizontal, sem a presença de achatamentos ocorridos no SPDC. Provavelmente, o desenvolvimento radicular no SPDNC foi beneficiado pela melhor capacidade de oxigenação e infiltração de água no solo, na camada de 8-16 cm (Tabela 3), em conseqüência da macroporosidade (Franzluebbers, 2002). Entretanto, na transição do BCCF para o BCSF, a quantidade de raízes diminuiu sensivelmente e, a partir da profundidade de $20 \mathrm{~cm}$, quando os estados estruturais das camadas de solo avaliadas tornaram-se mais homogêneos (BCSF e NAM, Figura $3 \mathrm{~F}$ e $\mathrm{H}$ ), a resistência à penetração e a quantidade de raízes não apresentaram diferenças (Figura 2 B e D, Figura 3 B e D).

Nos dois tratamentos, foi observado o empilhamento de agregados nas camadas de $0-5$ e $15-30 \mathrm{~cm}$ de profundidade (Piccinin et al., 2000), e a ocorrência de vazi-

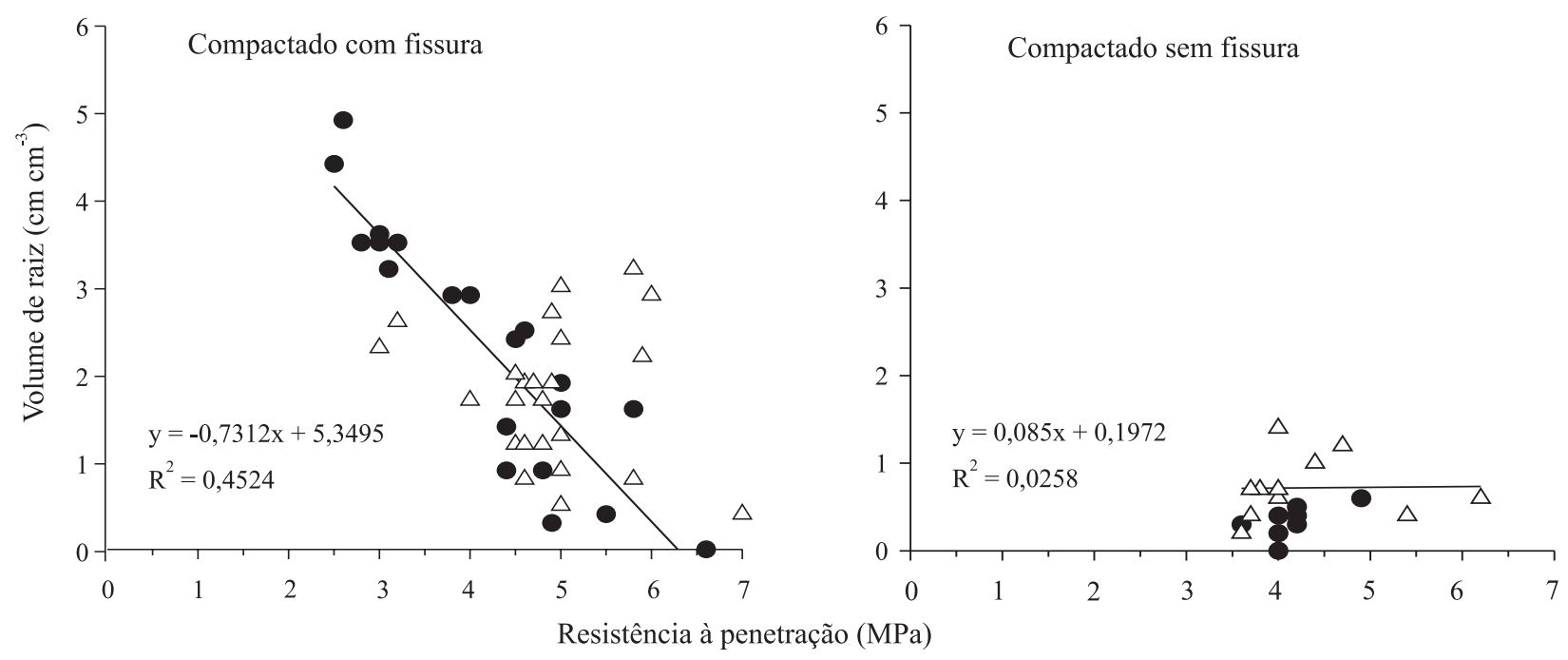

Figura 4. Correlação entre o volume de raízes de soja $\left(\mathrm{cm} \mathrm{cm}^{-3}\right)$ e a resistência do solo à penetração (MPa), na profundidade de 5-15 cm no sistema de plantio direto compactado (SPDC), nas estruturas compactada com fissuras e compactada sem fissuras, para as cultivares Embrapa-4 $(\triangle)$ e BR-16( $\bigcirc)$. 
os originados pela atividade biológica. O desenvolvimento das raízes, nas estruturas mais compactadas, se deu graças à atividade da fauna do solo, que desenvolve cavidades no perfil de solo, principalmente no sentido vertical, caracterizada pelo elevado crescimento radicular, o que mostra que o solo é capaz de recuperar um grau de compactação pelos processos biológicos e físicos (Holland, 2004).

As atividades exercidas pela fauna do solo ocorreram de forma acentuada, nos primeiros $40 \mathrm{~cm}$ de profundidade, nos tratamentos SPDNC e SPDC, com vazios contínuos no sentido vertical e cavidades de maiores diâmetros decorrentes das atividades da fauna (Figura $2 \mathrm{C}$ - abaixo de $30 \mathrm{~cm}$ de profundidade, na largura entre 70 e $90 \mathrm{~cm}$ do perfil - e Figura $3 \mathrm{~A}$ - na profundidade de $0-30 \mathrm{~cm}$, na largura de $85 \mathrm{~cm}$ do perfil).

\section{Conclusões}

1. A presença de estruturas compactadas diminui a exploração do sistema radicular da soja.

2. A cultivar Embrapa-4 apresenta maior crescimento radicular que a cultivar BR-16.

3. Não há correlação com o crescimento radicular e o estado de compactação do solo medido pelo penetrômetro.

4. A presença de camadas compactas no perfil do solo não afeta a produtividade de grão e a acumulação de matéria seca da soja, quando não há restrição hídrica.

\section{Agradecimentos}

A Donizete A. Loni, Luiz G. Garbelini e Mariluci S. Pires, pelas análises laboratoriais; a João R. Macedo, Paulo Volpato, Jorge J. Azevedo e Agostinho A. Silva, pelo suporte técnico; à Capes, pela concessão de bolsa de estudo.

\section{Referências}

ABREU, S.L.; REICHERT, J.M.; REINERT, D.J. Escarificação mecânica e biológica para redução da compactação em Argissolo franco-arenoso sob plantio direto. Revista Brasileira de Ciência do Solo, v.28, p.519-531, 2004.

BENGOUGH, A.G.; MULLINS, C.E. Mechanical impedance to root growth: a review of experimental techniques and root growth responses. Journal of Soil Science, v.41, p.341-358, 1990.
BEULTER, A.N.; CENTURION, J.F. Compactação do solo no desenvolvimento radicular e na produtividade da soja. Pesquisa Agropecuária Brasileira, v.39, p.581-588, 2004.

BEULTER, A.N.; CENTURION, J.F. Efeito do conteúdo de água e da compactação do solo na produção de soja. Pesquisa Agropecuária Brasileira, v.38, p.849-856, 2003.

BLAKE, G.R.; HARTGE, K.H. Bulk density. In: KLUTE, A. (Ed.). Methods of soil analyses: part 1. $2^{\text {nd }}$ ed. Madison: ASA, 1986. p.364-367. (Agronomy, 9).

BOHM, W. Methods of studying root systems. New York: SpringerVerlag, 1979. 194p.

BRONICK, C.J.; LAL, R. Soil structure and management: a review. Geoderma, v.124, p.3-22, 2005.

CAMARGO, O.A.; ALLEONI, L.R.F. Compactação do solo e o desenvolvimento das plantas. Piracicaba: Esalq, 1997. 132p.

DOMZAL, H.; SLOWINSKA-JURKIEWICZ, A. Effect of tillage and weather condition on the structure and physical properties of soil and yield of winter wheat. Soil and Tillage Research, v.10, p.225-241, 1987.

EMBRAPA. Centro Nacional de Pesquisa de Solos (Rio de Janeiro, RJ). Manual de métodos de análise de solo. 2.ed. Rio de Janeiro, 1997. 212p. (Embrapa-CNPS. Documentos, 1).

EMBRAPA SOJA. Recomendações técnicas para cultura da soja no Paraná 2000/2001. Londrina, 2000. 255p. (Embrapa Soja. Documentos, 145).

FRANZLUEBBERS, A.J. Water infiltration and soil structure related to organic matter and its stratification with depth. Soil and Tillage Research, v.66, p.197-205, 2002.

FREIXO, A.F.; MACHADO, P.L.O.A.; SANTOS, H.P.; SILVA, C.A.; FADIGAS, F.S. Soil organic carbon and fractions of Rhodic Ferralsol under the influence of tillage and crop rotation systems in southern Brazil. Soil and Tillage Research, v.64, p.221-230, 2002.

GENRO JUNIOR, S.A.; REINERT, D.J.; REICHERT, J.M. Variabilidade temporal da resistência à penetração de um Latossolo argiloso sob semeadura direta com rotação de culturas. Revista Brasileira de Ciência do Solo, v.28, p.477-484, 2004.

GREGORY, P.J. Crescimiento y funcionamiento de las raíces. In: WILD, A. (Coord.). Condiciones del suelo y desarrollo de las plantas según Russel. Madrid: Mundi-Prensa, 1992. p.121-175.

HOLLAND, J.M. The environmental consequences of adopting conservation tillage in Europe: reviewing the evidence. Agriculture, Ecosystems and Environment, v.103, p.1-25, 2004.

JOHNSON, J.F.; VOORHEES, W.B.; NELSON, W.W.; RANDALL, G.W. Soybean growth and yield as affected by surface and compaction. Agronomy Journal, v.82, p.973-979, 1990.

LAL, R. Conservation tillage for sustainable agriculture: tropics versus temperate environments. Advances in Agronomy, v.42, p.85-97, 1989.

LIPIEC, J.; STEPNIEWSKI, W. Effects of soil compaction and tillage systems on uptake and losses of nutrients. Soil and Tillage Research, v.35, p.37-52, 1995. 
MUZILLI, O. Influência do sistema de plantio direto, comparado ao convencional sobre a fertilidade da camada arável do solo. Revista Brasileira de Ciência do Solo, v.7, p.95-102, 1983.

NEVES, C.S.V.J.; FELLER, C.; GUIMARÃES, M.F.; MEDINA, C.C.; TAVARES FILHO, J.; FORTIER, M. Soil bulk density and porosity of homogeneous morphological units identified by the cropping profile method in clayey oxisols in Brazil. Soil and Tillage Research, v.71, p.109-119, 2003.

PICCININ, J.L.; ESPÍNDOLA, C.R.; TORRES, E. Condições morfoestruturais e estabilidade dos agregados do solo sob sistemas de semeadura direta e preparo convencional. In: REUNIÃO BRASILEIRA DE MANEJO E CONSERVAÇÃO DO SOLO E DA ÁGUA, 13., 2000, Ilhéus. Anais. Ilhéus: Ceplac, Cepec, 2000. v.1, p.246-247.

PIETOLA, L.M. Root growth dynamics of spring cereals with discontinuation of mouldboard ploughing. Soil and Tillage Research, v.80, p.103-114, 2004.

REICHARDT, K. Processos de transferência no sistema soloplanta-atmosfera. 4.ed. Campinas: Fundação Cargil, 1985. 443p.

RHEINHEIMER, D. dos S.; ANGHINONI, I. Distribuição do fósforo inorgânico em sistemas de manejo de solo. Pesquisa Agropecuária Brasileira, v.36, p.151-160, 2001.
SADRAS, V.O.; O’LEARY, G.J.; ROGET, D.K. Crop responses to compacted soil: capture and efficiency in the use of water and radiation. Field Crops Research, v.91, p.131-148, 2005.

SECCO, D.; REINERT, D.J.; REICHERT, J.M.; ROS, C.O. da. Produtividade de soja e propriedades físicas de um latossolo submetido a sistemas de manejo e compactação. Revista Brasileira de Ciência do Solo, v.28, p.797-804, 2004.

TAVARES FILHO, J.; RALISCH, R.; GUIMARÃES, M.F.; MEDINA, C.C.; BALBINO, L.C.; NEVES, C.S.V.J. Método do perfil cultural para avaliação do estado físico de solos em condições tropicais. Revista Brasileira de Ciência do Solo, v.23, p.393399, 1999.

TORMENA, C.A.; BARBOSA, M.C.; COSTA, A.C.S.; GONÇALVES, A.C.A. Densidade, porosidade e resistência à penetração em latossolo cultivado sob diferentes sistemas de preparo do solo. Scientia Agricola, v.59, p.795-801, 2002.

TORRES, E.; SARAIVA, O.F. Camadas de impedimento mecânico do solo em sistemas agrícolas com a soja. Londrina: EmbrapaCNPSo, 1999. 58p. (Embrapa-CNPSo. Circular técnica, 23).

VEPRASKAS, M.J. Plant response mechanisms to soil compaction. In: WILKINSON, R.E. Plant environment interactions. New York: M. Dekker, 1994. p.263-287.

Recebido em 6 de janeiro de 2005 e aprovado em 20 de julho de 2005 